\title{
PEDIATRIC HIV OUTBREAK IN PAKISTAN: POLICY IMPLICATIONS FROM GENERALIZED ARIMA
} ANALYSIS

\author{
Dr. Smartson. P. NYONI \\ ZICHIRe Project, University of Zimbabwe, Harare, Zimbabwe \\ Mr. Thabani NYONI \\ Department of Economics, University of Zimbabwe, Harare, Zimbabwe
}

\begin{abstract}
HIV/AIDS is increasingly becoming a nightmare in Pakistan. If left uncontrolled now, the country's limited resources could be overwhelmed by 2030 and this will cause worse sufferings and disease burden in the country. Using annual time series data on the number of children (ages 0 - 14) newly infected with HIV in Pakistan from 1990 - 2018, the study predicts the annual number of children who will be newly infected with HIV over the period 2019 - 2030. The study applied the BoxJenkins ARIMA technique. The diagnostic ADF tests show that, W, the series under consideration is an I (1) variable. Based on the AIC, the study presents the $\operatorname{ARIMA}(1,1,1)$ model as the parsimonious model. The residual correlogram further reveals that the estimated model is stable. The results of the study indicate that the number of new HIV infections in Pakistan is rising and on this trajectory, the country's limited resources will soon be overwhelmed. Our best model revealed that new pediatric HIV infections in Pakistan will continue to rise from the estimated 1460 to almost 1990 annual new infections by 2030. Amongst other policy directions, the study encourages the government of Pakistan to increase HIV awareness as well as expand PPTCT coverage throughout the country.
\end{abstract}

\subsection{INTRODUCTION}

HIV/AIDS is an increasingly growing public health threat endangering lives of millions of people around the globe (Ministry of National Health Services, Regulations \& Coordination, 2017). In the case of Pakistan, the disease is becoming more prevalent, and its death toll has been steadily increasing each year since 1987 when the first case was reported in the country (UNAIDS, 2014). The total number of HIV/AIDS infections in Pakistan has been increasing at an alarming rate; especially from 2005 to 2015, the number of reported infections in Pakistan ballooned from 8360 to 45990 cases, the highest global average increase of $17.6 \%$ in history (Khan \& Khan, 2012). The HIV/AIDS related death toll has also been on the rise: the number of deaths caused by HIV/AIDS in the country increased from 350 to a staggering number of 1480 between 2005 and 2015, which is tantamount to an average increase of 14.2\% per year (Ghani, 2016). Another serious issue related to the HIV epidemic in the country is that the Antiretroviral Therapy (ART), a drug regimen that is critical in the treatment of the HIV/AIDS (Bhatti et al., 2016), is neither easily available nor easily accessible in Pakistan (Hussain et al., 2018); only a "spoonful" individuals suffering from HIV/AIDS receives ART drugs for treatment (Yusufzai, 2011). This has exposed the lives of HIV positive people in the country, especially the innocent children. Pediatric HIV is dramatically becoming a serious problem in Pakistan. The recent HIV outbreak in Sindh Province in the country is one good example. Possible drivers of the outbreak seem to indicate unsafe practices of blood transfusion and re-use of injection needles and syringes, although this is being further investigated (WHO, 2019). The main goal of this study is to predict the number of children newly infected with HIV in Pakistan over the period $2019-2030$. This study will go a long way in assessing the possibility of ending pediatric HIV in the country.

\subsection{LITERATURE REVIEW}

Khalid \& Fox (2019) investigated how policy actors tasked with implementing HIV programs navigate the competing demands placed upon them by development targets and national policies, particularly in the current context of waning international investments towards HIV. The authors interviewed 29 key informants comprising health experts in donor organizations and government employees in HIV programs in Pakistan. The research found out that in Pakistan there is low and heterogeneous political commitment for HIV, which has led to low HIV treatment coverage in the country. Nawaz et al. (2019) investigated the outbreak of HIV/AIDS in Larkana district in Pakistan. In order to find out the epidemiologic links of this outbreak, the authors relied upon a cross-sectional study. The study results indicate that the use of contaminated syringes in local clinics, home-based circumcision, as well as re-use of razor blades by barbers were the most probable links with the 2019 HIV outbreak in the country. In a recent study, Siddiqui et al (2020) examined pediatric HIV in Pakistan. A matched case-control study was done with 406 cases recruited. Conditional logistic regression was employed to determine the association of a priori defined risk factors with HIV infection. Furthermore, global positioning system coordinates of participants' addresses were collected to analyze concordance between the genetic and spatial epidemiology. At the time of preparing this research article, the final results of the study by Siddiqui et al. (2020) had not been released but their study is expected to provide information on the likely routes of infection and drivers of the HIV outbreak among children in Pakistan. Studies that forecast new HIV infections in children in Pakistan are relatively scanty. It is this information hiatus that this paper seeks to close. 


\subsection{The Box - Jenkins (1970) Methodology}

\subsection{METHODODOLOGY}

The first step towards model selection is to difference the series in order to achieve stationarity. Once this process is over, the researcher will then examine the correlogram in order to decide on the appropriate orders of the AR and MA components. It is important to highlight the fact that this procedure (of choosing the AR and MA components) is biased towards the use of personal judgement because there are no clear - cut rules on how to decide on the appropriate AR and MA components. Therefore, experience plays a pivotal role in this regard. The next step is the estimation of the tentative model, after which diagnostic testing shall follow. Diagnostic checking is usually done by generating the set of residuals and testing whether they satisfy the characteristics of a white noise process. If not, there would be need for model re specification and repetition of the same process; this time from the second stage. The process may go on and on until an appropriate model is identified (Nyoni, 2018c). This approach will be used to analyze, W, the series under consideration. 3.2 The Applied Box - Jenkins ARIMA Model Specification

If the sequence $\Delta^{\mathrm{d}} \mathrm{W}_{\mathrm{t}}$ satisfies an ARMA (p, q) process; then the sequence of $\mathrm{W}_{\mathrm{t}}$ also satisfies the ARIMA (p, d, q) process such that:

$$
\Delta^{d} W_{t}=\sum_{i=1}^{p} \beta_{i} \Delta^{d} L^{i} W_{t}+\sum_{i=1}^{q} \alpha_{i} L^{i} \mu_{t}+\mu_{t}
$$

where $\Delta$ is the difference operator, vector $\beta \in \mathrm{R}^{\mathrm{p}}$ and $\mathrm{a} \in \mathrm{R}^{\mathrm{q}}$.

\subsection{Data Collection}

This study is based on annual observations (that is, from 1990 - 2018) on the number of children newly infected with HIV (ages 0 - 14) [denoted as W] in Pakistan. Out-of-sample forecasts will cover the period $2019-2030$. All the data was collected from the World Bank online database.

\subsection{Diagnostic Tests \& Model Evaluation}

\subsubsection{Stationarity Tests: Graphical Analysis}

Figure 1

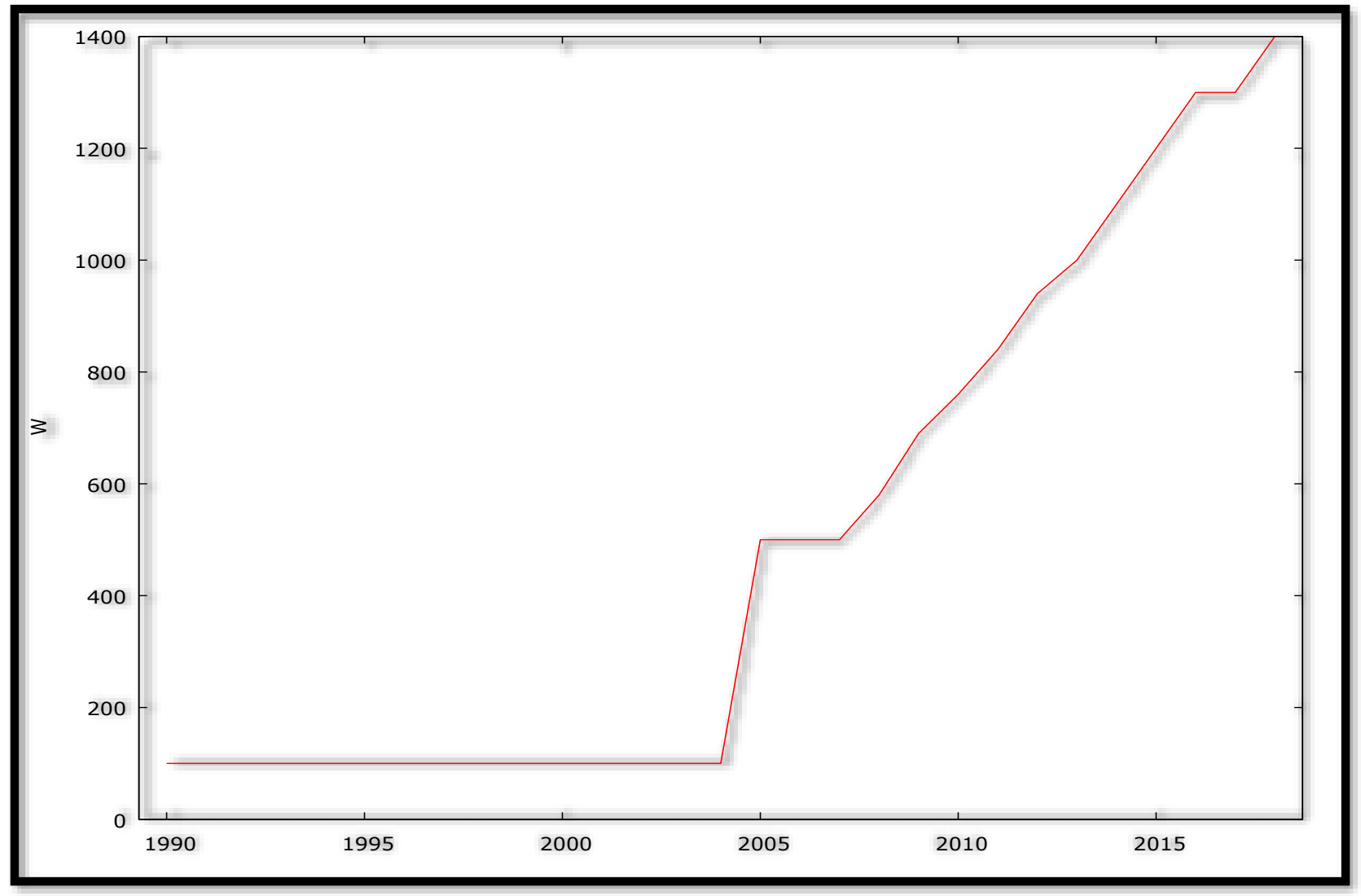

\subsubsection{The Correlogram in Levels}

Figure 2: Correlogram in Levels 


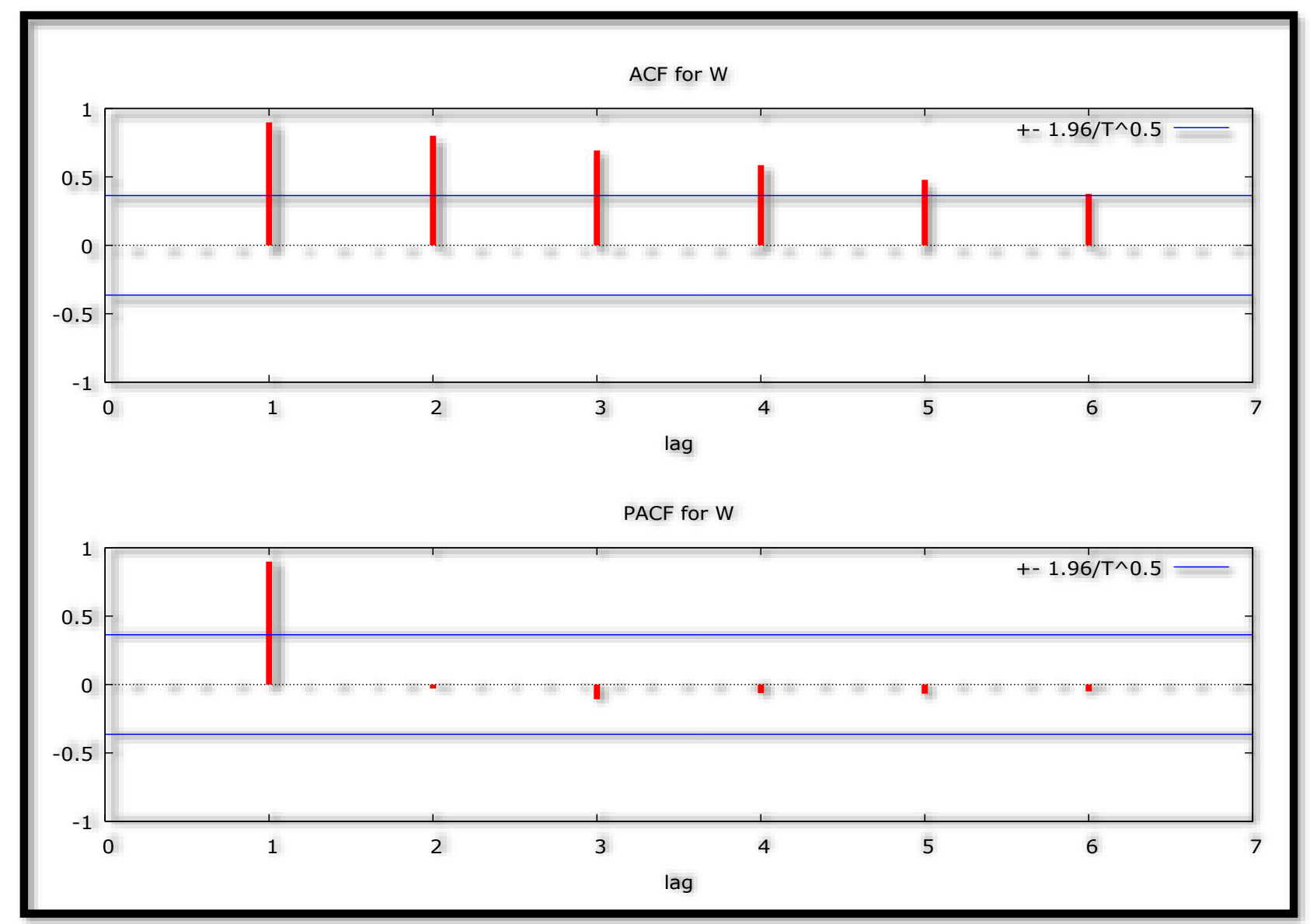

3.4.3 The ADF Test in Levels

Table 1: with intercept

\begin{tabular}{|c|c|c|c|c|c|}
\hline Variable & ADF Statistic & Probability & \multicolumn{2}{|c|}{ Critical Values } & Conclusion \\
\hline $\mathrm{W}$ & 1.437526 & 0.9986 & -3.689194 & @ 1\% & Non-stationary \\
\hline & & & -2.971853 & $@ 5 \%$ & Non-stationary \\
\hline & & & -2.625121 & @ 10\% & Non-stationary \\
\hline
\end{tabular}

Table 1 shows that $\mathrm{W}$ is not stationary in levels, as already suggested by figure 1 and 2 .

3.4.4 The Correlogram (at First Differences)

Figure 3: Correlogram (at First Differences) 


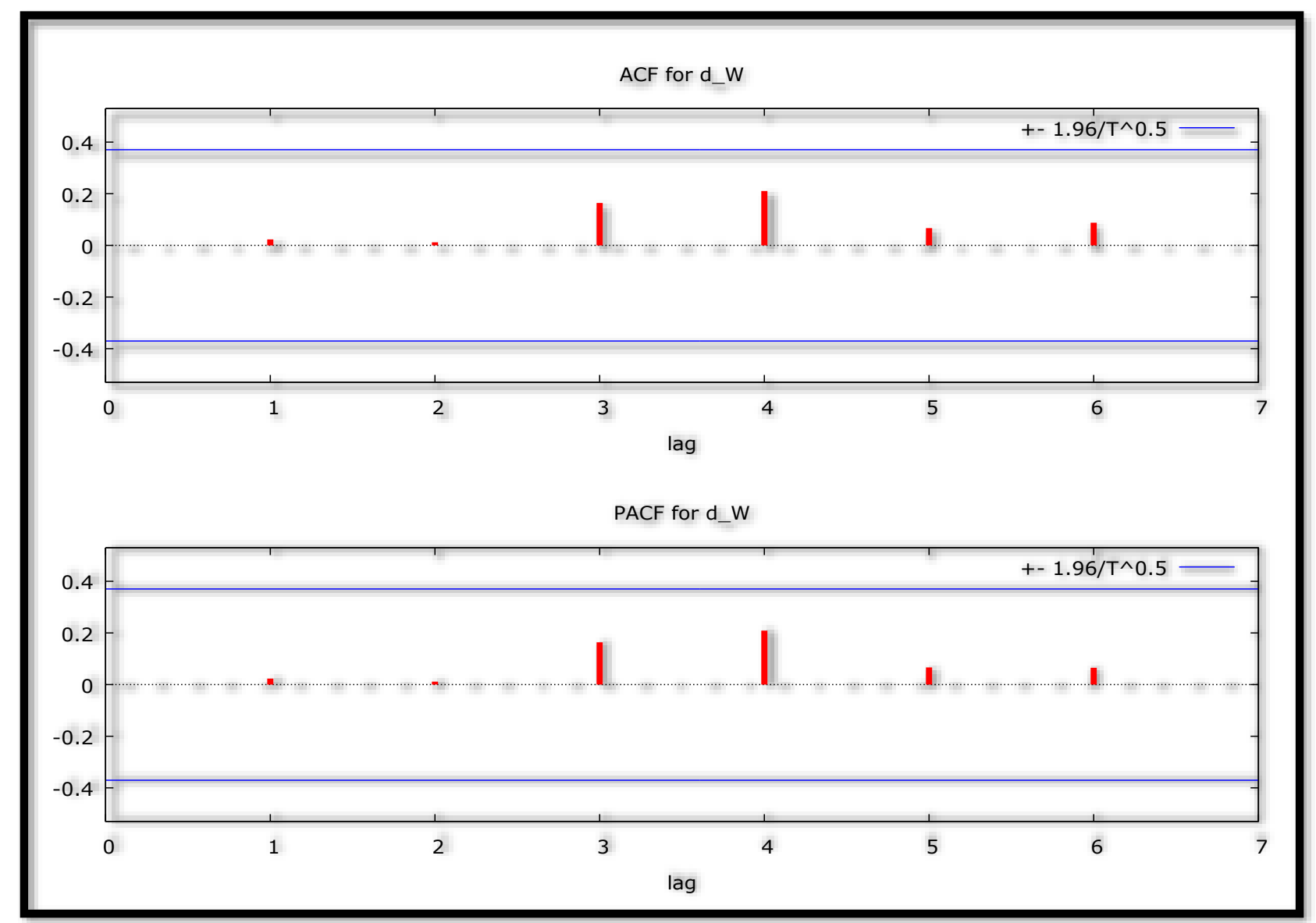

\subsubsection{The ADF Test (at First Differences)}

Table 2: with intercept

\begin{tabular}{|c|c|c|c|c|c|}
\hline \multirow{2}{*}{$\frac{\text { Variable }}{\Delta \mathrm{W}}$} & ADF Statistic & Probability & \multicolumn{2}{|c|}{ Critical Values } & Conclusion \\
\hline & -4.871374 & 0.0006 & -3.699871 & @ 1\% & Stationary \\
\hline & & & -2.976263 & @ 5\% & Stationary \\
\hline & & & -2.627420 & @ 10\% & Stationary \\
\hline
\end{tabular}

Figure 3 and table 2 indicate that $\mathrm{W}$ is an I (1) variable.

3.4.6 Evaluation of ARIMA models (with a constant)

Table 3: Evaluation of ARIMA Models (without a constant)

\begin{tabular}{|l|l|l|l|l|l|}
\hline Model & AIC & U & ME & RMSE & MAPE \\
\hline ARIMA $(1,1,1)$ & $\mathbf{3 3 2 . 5 3 2 2}$ & 0.9976 & 21.221 & 81.524 & 5.2422 \\
\hline ARIMA $(1,1,0)$ & 335.5301 & 1.0001 & 35.434 & 90.02 & 6.4564 \\
\hline ARIMA $(2,1,0)$ & 336.4 & 0.99998 & 29.333 & 88.101 & 6.5688 \\
\hline ARIMA $(0,1,1)$ & 336.0312 & 0.99988 & 39.356 & 90.874 & 6.598 \\
\hline ARIMA $(2,1,2)$ & 334.6432 & 0.99644 & 18.394 & 78.335 & 4.2104 \\
\hline
\end{tabular}

A model with a lower AIC value is better than the one with a higher AIC value (Nyoni, 2018b) Similarly, the U statistic can be used to find a better model in the sense that it must lie between 0 and 1 , of which the closer it is to 0 , the better the forecast method (Nyoni, 2018a). In this research paper, only the AIC is used to select the best model. Therefore, the ARIMA $(1,1,1)$ model is finally selected.

3.5 Residual \& Stability Tests

3.5.1 Correlogram of the Residuals of the ARIMA $(1,1,1)$ Model

Figure 4: Correlogram of the Residuals 


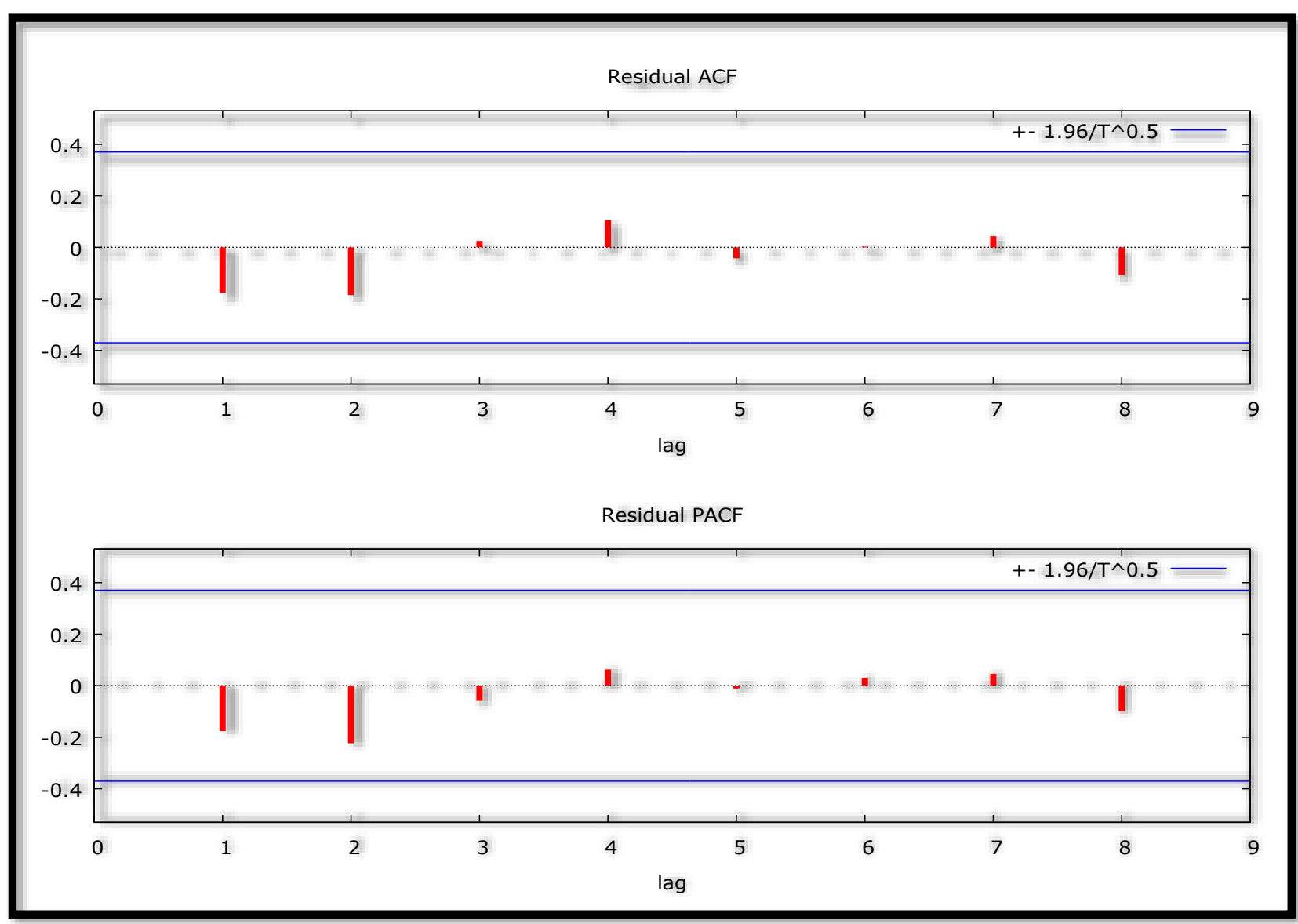

Figure 4 indicates that the estimated model is adequate since ACF and PACF lags are quite short and within the bands.

\subsection{Descriptive Statistics}

\section{FINDINGS OF THE STUDY}

Table 4: Descriptive Statistics

\begin{tabular}{|l|l|}
\hline Description & Statistic \\
\hline Mean & 486.55 \\
\hline Median & 100 \\
\hline Minimum & 100 \\
\hline Maximum & 1400 \\
\hline
\end{tabular}

Over the study period, the annual average number of new pediatric HIV infections in Pakistan is approximately 487. The minimum number of infections is 100 and this has been observed over the period $1990-2004$. The maximum number of infections is 1400 and has been recorded in 2018.

\subsection{Results Presentation ${ }^{1}$}

Table 5: Main Results

ARIMA (1, 1, 1) Model:

The estimated optimal model, the ARIMA $(1,1,1)$ model can be expressed as follows:

$$
\Delta W_{t}=0.964364 \Delta W_{t-1}-0.822114 \mu_{t-1}
$$

\begin{tabular}{|c|l|l|l|l|}
\hline Variable & Coefficient & Standard Error & $\mathrm{z}$ & $\mathrm{p}$-value \\
\hline$\beta_{1}$ & 0.964364 & 0.174227 & 5.535 & $0.0000^{* * *}$ \\
\hline$\alpha_{1}$ & -0.822114 & 0.314575 & -2.613 & $0.0090^{* * *}$ \\
\hline
\end{tabular}

Table 5 shows the main results of the ARIMA $(1,1,1)$ model.

\footnotetext{
${ }^{1}$ The *, ** and *** imply statistical significance at $10 \%, 5 \%$ and $1 \%$ levels of significance; respectively.
} 
Figure 5: Forecast Graph - In \& Out-of-Sample Forecasts

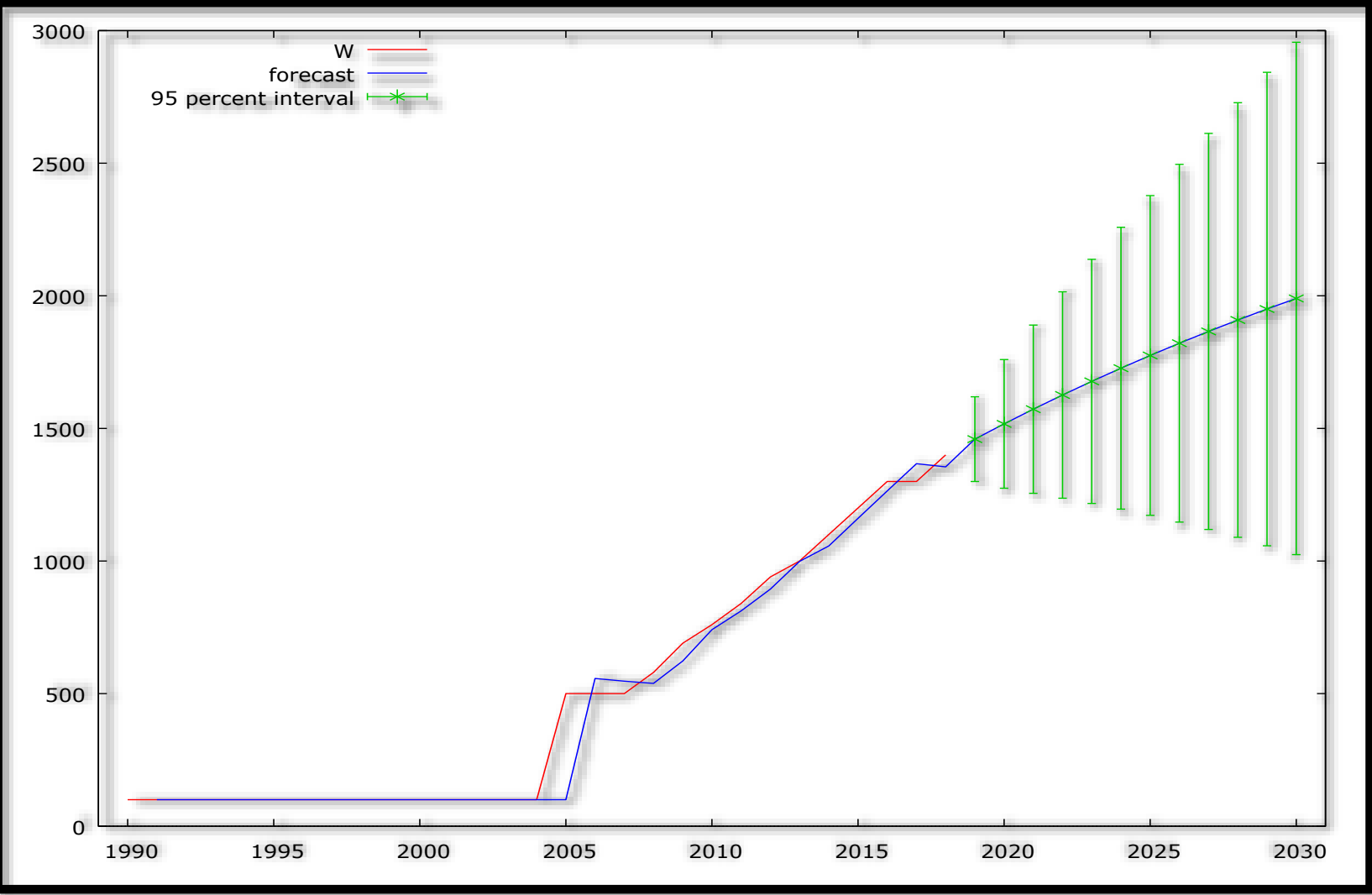

Figure 5 shows the in-and-out-of-sample forecasts of W. The out-of-sample forecasts cover the period $2019-2030$. Predicted W-Out-of-Sample Forecasts Only

Table 6: Predicted W

\begin{tabular}{|l|l|l|l|}
\hline Year & Prediction & Standard Error & 95\% Confidence Interval \\
\hline 2019 & 1459.57 & 81.5006 & $(1299.83,1619.31)$ \\
\hline 2020 & 1517.02 & 123.729 & $(1274.51,1759.52)$ \\
\hline 2021 & 1572.42 & 161.808 & $(1255.28,1889.55)$ \\
\hline 2022 & 1625.84 & 198.544 & $(1236.70,2014.98)$ \\
\hline 2023 & 1677.36 & 234.859 & $(1217.05,2137.68)$ \\
\hline 2024 & 1727.05 & 271.134 & $(1195.64,2258.46)$ \\
\hline 2025 & 1774.96 & 307.542 & $(1172.19,2377.74)$ \\
\hline 2026 & 1821.17 & 344.159 & $(1146.63,2495.71)$ \\
\hline 2027 & 1865.73 & 381.008 & $(1118.97,2612.49)$ \\
\hline 2028 & 1908.71 & 418.091 & $(1089.26,2728.15)$ \\
\hline 2029 & 1950.15 & 455.392 & $(1057.60,2842.70)$ \\
\hline 2030 & 1990.11 & 492.890 & $(1024.07,2956.16)$ \\
\hline
\end{tabular}

Figure 6: Graphical Analysis of Out-of-Sample Forecasts 


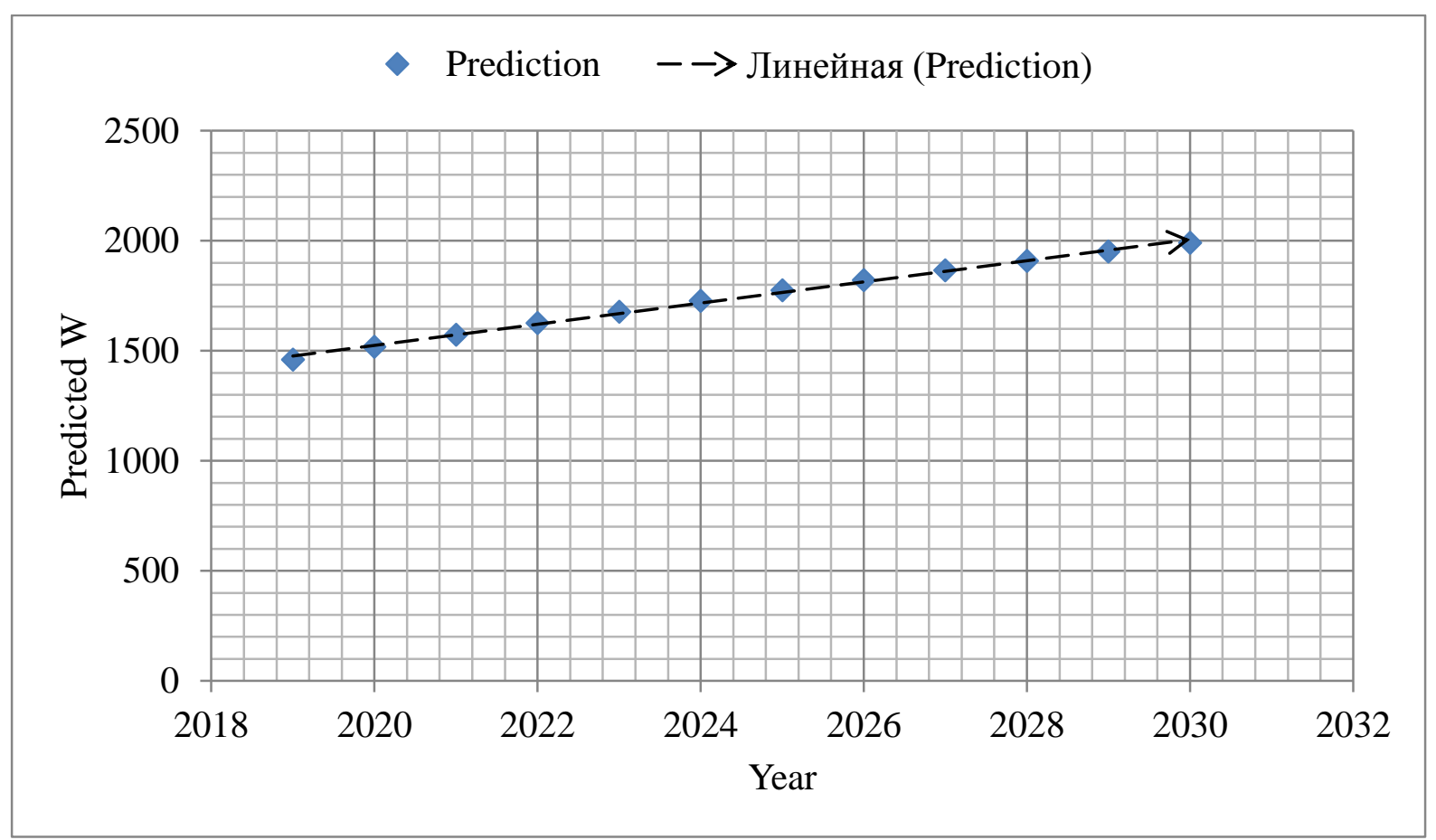

Table 6 and figure 6 show the out-of-sample forecasts only. The number of new HIV infections in children in Pakistan is projected to continue to rise rapidly from the estimated 1460 in 2019 to approximately 1990 new infections by 2030. The results of the study are not surprising given the findings made by Nawaz et al. (2019).

\section{CONCLUSION}

The study indicates that the ARIMA $(1,1,1)$ model is not only stable but also the most suitable model to forecast the annual number of new HIV infections in children in Pakistan over the period 2019 - 2030. The model predicts a sharp increase in the annual number of new pediatric HIV infections in the country. The study recommends that the government of Pakistan should intensify HIV prevention and control programmes in the country, for example, the Prevention of Parentto-Child Transmission (PPTCT) of HIV programme. In this regard, the government of Pakistan should also make sure that they expand on PPTCT coverage throughout the country. The intensification of the District Family Health Day Model (DFHDM) as a strategy for increasing HIV awareness in the general population is recommendable. Last but not least, there is need for psychological support for families and communities affected by HIV in the country.

\section{REFERENCES}

[1] Bhatti, A. B., Usman, M., \& Kandi, V. (2016). Current Scenario of HIV/AIDS, Treatment Options, and Major Challenges with Compliance to Antiretroviral Therapy, Cureus, 8 (3): 1 - 15.

[2] Ghani, A. (2016). HIV/AIDS Cases on the Rise in Pakistan, The Express Tribune, accessed on 01/08/2020.

[3] Hussain, A., et al. (2018). HIV/AIDS - A Growing Epidemic in Pakistan, Journal of Evolution of Medical and Dental Sciences, 7 (8): 1057 - 1062.

[4] Khalid, H., \& Fox, A. M. (2019). Political and Governance Challenges to Achieving Global HIV Goals with Injecting Drug Users: The Case of Pakistan, International Journal of Health Policy and Management, 8 (5): 261 $-271$.

[5] Khan, A. A., \& Khan, A. (2012). Sexually Transmitted Infection Care in Pakistan: The Providers' Perspective, Journal of Pakistan Medical Association, 62 (9): 941 - 945.

[6] Ministry of National Health Services, Regulations \& Coordination (2017). AIDS Epidemic Modelling Exercise for Pakistan 2017, Ministry of National Health Services, Regulations \& Coordination, Government of Pakistan.

[7] Nawaz, A., et al. (2019). Outbreak of HIV/AIDS in Very Low Risk Population in District Larkana, Pakistan: Cross Sectional Study, Indian Journal of Pure and Applied Biosciences, 7 (4): 38 - 40.

[8] Nyoni, T (2018b). Modeling and Forecasting Inflation in Kenya: Recent Insights from ARIMA and GARCH analysis, Dimorian Review, 5 (6): 16 - 40.

[9] Nyoni, T. (2018a). Modeling and Forecasting Naira/USD Exchange Rate in Nigeria: A Box-Jenkins ARIMA Approach, MPRA Paper No. 88622, University Library of Munich, Munich, Germany.

[10] Nyoni, T. (2018c). Box - Jenkins ARIMA Approach to Predicting net FDI inflows in Zimbabwe, MPRA Paper No. 87737, University Library of Munich, Munich, Germany. 
[11] Siddiqui, A. R., et al. (2020). Investigation of an Extensive Outbreak of HIV Infection Among Children in Sindh, Pakistan: Protocol for a Matched Case-Control Study, BMJ Open, 10: $1-8$.

[12] UNAIDS (2014). Global AIDS Response Progress Report, UNAIDS, Islamabad.

[13] WHO (2019). HIV Outbreak in Sindh Province, WHO, Geneva.

[14] Yusufzai, A. (2011). AIDS Drugs Access Fraught with Hazard for Pakistan's Tribal Regions, The Guardian News and Media, accessed on 01/08/2020. 